Gut, 1964, 5, 488

\title{
Experience of a new procedure for faecal analysis
}

\author{
W. C. WATSON AND CHRISTINE DICKSON \\ From the Department of Medicine, Royal Infirmary, Glasgow
}

Recently Jover and Gordon (1962) described a new method for the collection and homogenization of faeces. In the same paper they introduced a modification of the van de Kamer procedure (van de Kamer, ten Bokkel Huinink, and Weyers, 1949) which, by the substitution of toluene for petroleum ether, permitted the extraction of hydroxy fatty acids. Their report, however, was concerned chiefly with technique and their clinical experience of the method was limited.

In this paper we report our experience with the method, define the range of normal values for faecal fat, indicate its great versatility for a wide range of investigations, and at the same time draw attention to a procedure which abolishes the unpleasantness associated with work requiring the handling and disposal of faeces.

\section{METHODS}

The principal features of the method are the use of a rigid disposable container (a paint can) for the collection of faeces, and vigorous shaking, rather than blending, for homogenization. With few and only minor exceptions the method used was that described in working detail by the original authors (Jover and Gordon, 1962). An improved cellulose gum, type CMC 7HSXP in $1 \%$ solution, was used instead of type $70 \mathrm{High}^{1}$ and a paint shaking machine $^{2}$ of British manufacture proved to be as effective as the American equivalent. One gallon paint cans were obtained in bulk from a local supplier. If no chemical analysis of faecal mineral or electrolytes is required, washed granite chips can be substituted for the coarse granular silica.

The hydrolysis, extraction, and titration procedures for the estimation of fatty acids were exactly as described by the authors. The faecal homogenate is also suitable for the preparation of methyl esters for gas-liquid chromatography (Watson, Gordon, Karmen, and Jover, 1963).

The method is ideal for isotopic balance studies involving the absorption of $\mathbf{I}^{131}$-labelled triglycerides and fatty acids, $\mathrm{Co}^{58}$-labelled vitamin $\mathrm{B}_{12}$ and, $\mathrm{Fe}^{59}$-labelled iron, or for the measurement of the loss of circulating $\mathrm{Cr}^{51}$-labelled red cells or $\mathbf{I}^{131}$-labelled polyvinyl pyrrolidone (P.V.P.) into the gut. The prepared, unopened can

${ }^{1}$ Hercules Powder Co. Ltd., London.

'Speedy Agitator Holmes Bros., London. is placed on top of a well-type scintillation counter enclosed within a 2 in. thick lead shield. A suitable standard is made up to the same volume, with water, in another can.

The contents of the can are safely and easily emptied into a lavatory pan or slunge.

Where faecal fat estimations only were required, four-day collections were taken from patients on ordinary ward diet. Collections weighing less than $200 \mathrm{~g}$. were discarded as unlikely to be representative. For isotope studies six-day collections were made and these samples were also used for faecal fat estimations.

\section{MATERIALS}

Two groups of patients were studied. The 'normal', or control group, comprised 128 convalescent patients on full ward diet, without diarrhoea or any other disorder likely to be associated with steatorrhoea. The 'abnormal' or steatorrhoea group was made up of 57 patients whose final diagnosis included post-gastrectomy steatorrhoea, duodenal carcinoma, biliary cirrhosis, reticulo-sarcoma involving the mesenteric lymphatics, adult coeliac disease, tuberculous enteritis, pancreatic calculus, and idiopathic steatorrhoea.

\section{RESULTS}

The normal results, expressed as milliequivalents (mEq.) of faecal fatty acid per day, and based on 128 analyses, are summarized as follows: Range, 3.1-22.6; mean, 9.8; standard deviation (S.D.), 3.7; $95 \%$ normal range (mean \pm 2 S.D. $)=2 \cdot 4-17 \cdot 2$.

Only four of the control results were greater than $17.0 \mathrm{mEq}$./day and this was taken as the upper limit of normal. Only three readings fell within the range $15 \cdot 1-17.0 \mathrm{mEq}$./day, which suggests that the transition from normal to abnormal is in practice fairly sharp.

On the basis of these control figures 54 of the 57 patients under investigation for the malabsorption syndrome had biochemical steatorrhoea with faecal fatty acid values ranging from $17 \cdot 1$ to $112.0 \mathrm{mEq}$./ day. This laboratory result was consistent with the overall clinical picture. The three remaining subjects had figures of $15 \cdot 2,15 \cdot 6$, and $17.0 \mathrm{mEq}$./day and were being investigated respectively for post- 
gastrectomy diarrhoea (2) and chylothorax associated with reticulo-sarcoma involving the cysterna chyli and lower part of the thoracic duct.

\section{DISCUSSION}

A method for the handling, disposal, and analysis of faeces described by Jover and Gordon (1962) deserves to be better known. It has been used exclusively in this laboratory for 18 months and we would corroborate the advantages claimed for it by the authors. One gallon paint cans bought in bulk, cost about 1s. 1d. each and add little to the cost of the procedure; moreover they are suitable for outpatient collections.

The method has considerable advantages for isotope studies. It is often not appreciated by investigators that the geometric requirements of faecal counting are not properly met by the counting of faecal samples of variable volume in containers surrounded by a ring of Geigers. Here the faecal collection is brought to constant volume and compared with a standard of similar volume under symmetrical counting conditions. A particularly useful application for the method is in the estimation of alimentary blood loss using chromium ${ }^{51}$-labelled red cells. Significantly accurate readings can be obtained by 1,000 second counting periods.

The results for faecal fat excretion are expressed as milli-equivalents of fatty acid. This is to be recommended for any method which is based on the titration of fatty acids. The conversion of milliequivalents of fatty acids to grams of fat involves assumptions which are variable and approximate. In any case this conversion is unnecessary. The upper limit of normal for faecal fat excretion by this method is $17.0 \mathrm{mEq}$. fatty acid per day.

We thank Professor McGirr for his interest and help in setting up the facilities for the methods referred to in this paper.

One of us (W.C.W.) was supported in part by U.S. Public Health Services Returning Fellow Grant RF$35 / \mathrm{Cl}$.

\section{REFERENCES}

Jover, A., and Gordon, R. S. Jr. (1962). Procedure for quantitative analysis of feces with special reference to fecal fatty acids. J. Lab. clin. Med., 59, 878-884.

Kamer, J. H. van de., Huinink, H. ten Bokkel, and Weyers, H. A (1949). Rapid method for the determination of fat in faeces. J. biol. Chem., 177, 347-355.

Watson, W. C., Gordon, R. S. Jr., Karmen, A., and Jover, A. (1963). The absorption and excretion of castor oil in man. J. Pharm. Pharmacol., 15, 183-188. 